DOI: https://dx.doi.org/10.33289/IJRPC.12.10.2021.11(38)

\title{
UTILIZATION AND MEDICATION ADHERENCE OF HYPERTENSIVE PATIE NTS FROM THE CITY OF MALOLOS, BULACAN
}

\author{
KN. Getutua ${ }^{1 *}$, KS. Gamit ${ }^{1}$, A. Maniego ${ }^{1}$, VA. Ortega ${ }^{1}$, \\ N. Santos ${ }^{1}$, R. Jazul ${ }^{1,2}$ and P. David ${ }^{1,2}$ \\ 1Department of Pharmacy, Centro Escolar University, \\ Malolos, Bulacan, Philippines. \\ ${ }^{2}$ Graduate School, Centro Escolar University, \\ Manila, Philippines.
}

\section{ABSTRACT}

Medicine utilization and medication adherence is a crucial factor for managing chronic diseases. Among cardiovascular diseases, hypertension is the most common type of cardiovascular disease and can preclude a different kind of cardiovascular disease. Hypertension and its related conditions are considered the foremost cause of death due to lack of awareness, poor compliance, and improper management approach. This study determined the utilization and medication adherence of hypertensive patients from the City of Malolos, Bulacan. This descriptive quantitative study has utilized convenience sampling and used Survey-questionnaire as a data-gathering tool. A total of 251 respondents were qualified and accomplished the questionnaires. Most of the participants were female ages 41-60 years old college graduates, self-employed, and family income below 10,000 . Out of 251 respondents, $28 \%$ do not have comorbidities. The majority had $<4$ medical check-ups made in the past three months and were diagnosed with hypertension for $<5$ years; adherence of the $65 \%$ of the participants was rated low. Age and monthly family income showed a significant relationship with medication adherence. A significant relationship between comorbidities with the number of antihypertensive medications and patients' adherence behavior was observed. The adherence rate of the population is low. Factors affecting patients' adherence and medication utilization are family income and their age. Most of the respondents believe in natural remedies rather than medicines in terms of safeness and difficulty in taking the medication at the right time affects their adherence.

Keywords: Hypertension, Correlation, Clinical data and Medication beliefs.

\section{INTRODUCTION}

Medicine utilization and medication adherence is a crucial factor for managing lifelong or chronic diseases. Chronic diseases are defined by the Center for Disease Control and Prevention (CDC) as "conditions that last one year or more and require ongoing medical attention or limit activities of daily living or both." Chronic diseases such as cardiovascular diseases, cancer, and diabetes are notoriously known as the primary cause of fatalities and disabilities worldwide. However, out of these three given chronic diseases, cardiovascular diseases remain on their throne for being the leading cause of death for the past twenty years. (World Health Organization, 2019).

Hypertension or high blood pressure is the most common type of cardiovascular disease, and it is also the origin of other kinds of cardiovascular disease. Hypertension occurs when there is an alteration in cardiac output and peripheral vascular resistance (Lapum, 2017). Since hypertension is progressive and 
incurable, disease management is the main goal to improve patients' quality of life. Pharmacological therapy for hypertension has been widely used globally. Subsequently, different kinds of hypertensive drugs have been released in the market with varying dosages and patient utilization regimens assigned to them distinctively. As the dosage regimen becomes complicated, patients' adherence and medication utilization can affect patients' quality of life.

This study determined the factors affecting patients' adherence and medication utilization of hypertensive patients around Malolos, Bulacan. This study was accomplished by gathering patients' information about their socio-demographic profile, clinical data, drug therapy data and assessing the barriers and factors affecting their adherence to antihypertensive medication. This assessment will be significant for healthcare practitioners dealing with patients with hypertension. This research study can also be beneficial for patients with hypertension to prevent its progression in another type of disease.

\section{MATERIALS AND METHODS}

The study utilized a descriptive quantitative research design. The researcher's developed a modified survey questionnaire that registered pharmacists have validated in different pharmacy practices, non-health allied professionals, and hypertensive patients. This modified questionnaire will be used to answer the objectives of the study.

\section{Setting of the Study}

The study has been conducted in Malolos Bulacan, Philippines, from November 2020 to May 2021. The City of Malolos has 5,097 cases, making it the 3rd leading municipality with the highest cases of hypertension in the province.

\section{Subjects of the Study}

The target population of the study is hypertensive patients. This study utilized a convenience sampling method, and by using Raosoft Software with a $90 \%$ confidence level and $5 \%$ margin of error, the researchers identified the target number of respondents. The total number of respondents who participated in the study is 251 hypertensive patients. The inclusion criteria are the following: (1) diagnosed with HTN, (2) residing in Malolos Bulacan, (3) taking antihypertensive medication, (4) with valid prescription, (5) male or female (6) aged 18 and above. However, pregnant women were excluded from the subject of the study.

\section{Data Collection}

In collecting the data, the researchers used the validated questionnaire and sent it to the respondents via Google Forms through social media and messaging platforms. The questionnaire consisted of questions regarding their socio-demographic profile, clinical and drug therapy data, and the barriers and factors that affect their medication adherence. Permission or consent letter before conducting the survey is also indicated in the Google Form.

The scientific and ethical protocol used was approved in April 2021 by the Institutional Ethics and Review Committee (IERC) of Centro Escolar University as part of the requirements in using human subjects for the research.

\section{Data Analysis}

The researchers used Stata/IC 13 and Microsoft Excel to enter data, manage, and analyze all the data collected. The data was presented using frequency, percentage mean value, standard deviation (SD), and rank as appropriate. The data will be interpreted using a descriptive statistical method that will be simplified using percentage and frequency. A chi-squared test was utilized in order to identify the relationship between the demographic profile and clinical data related to drug utilization and adherence. The confidence interval $(\mathrm{Cl})$ used is $90 \%$, and a probability value of $<0.05$ and $<0.01$ has been used to indicate the relationship between the used variables.

\section{RESULTS AND DISCUSSION}

From among the data that has been analyzed and interpreted, most of the hypertensive respondents are female from the age group of 41-60 years old college graduates, selfemployed, and with family income below $\mathrm{P} 10,000$, as shown in Table 1. Hypertension is a highly prevalent modifiable risk factor for CVD and one of the major causes of death in women worldwide. Young women are protected from developing hypertension, in part, by endogenous estrogen. As women age, they become more likely to develop hypertension and CVD outcomes (Ahmad and Oparil 2017). Hypertension prevalence in women exceeds men beginning about 50-60 years of age (Wenger et al., 2018).

Out of 251 respondents, $28.29 \%$ don't have comorbidities. Among the respondents' top 5 present diseases are Endocrine Diseases, Musculo- Skeletal diseases, Cardiovascular Diseases, Immune system Disorder, and hematological disorders. With comorbidities combined, it will outweigh the number of those 
respondents with no other conditions. Patients' medical check-ups within the past three months were assessed. Responses of less than four medical check-ups for the past comprises $88.05 \%$ of the population. While those who had more than four medical check ups were only $11.95 \%$. Most of them were diagnosed with hypertension for less than five years $(51 \%)$, while the remaining $(49 \%)$ is more than five years.

The majority of the participants used one medication with a corresponding percentage of $49.80 \%$, followed by two drugs with $40.24 \%$. It means that the majority of the patients do have mild hypertension (Mann, 2020). However, for those with comorbidities, combination therapy might be necessary. Losartan is the most used drug with a percentage of $58.17 \%$. It means that for respondents with present comorbidities, Losartan is beneficial not only to treat hypertension but also to treat other comorbidities such as heart failure and help kidneys work better; if you have diabetes, the said drug can also be utilized in combination therapy (Sison et al., 2019). Angiotensin Receptor Blocker remains the most used with $71.31 \%$, followed by Calcium Channel Blockers with $60.16 \%$.

$59 \%$ of the hypertensive patients said that the cost of their antihypertensive medications per month is below 1,000 pesos. One of the contributing factors that affect the costs of their antihypertensive medication is that most respondents are taking one antihypertensive drug, and most of them are only diagnosed with HTN for less than five years. Hypertensive patients in India cannot afford to purchase their medicine due to their low capacity to pay and high-priced drugs compared to other low-income countries considering that the Philippines belongs to this group (Attaei et al., 2017).

In the adverse drug reaction experienced by the respondents, data presented in Table 1 indicates that the majority of the respondents do not experience adverse drug reactions. However, the most dominant ADR experienced by the respondents is dizziness, urinary incontinence, coughing, \& falls.

There as where respondents most have difficulties with adherence to dosage regimens show that the right time ranks the highest while the right route is the lowest.

For Table 2, different barriers to adherence of respondents to antihypertensive medications have been identified. These barriers are classified as intentional, unintentional, medication-related, and health-related barriers. The study results show that intentional, health-related, and medication- related barriers are present among the respondents. The overall mean is $3.04 \pm 0.7916$, in which the majority of the respondents agree with the statements regarding these barriers.

Table 3 shows the factors affecting adherence to antihypertensive medication. It is presented with the respondents' beliefs, which are further grouped according to medication necessity and patients' concerns. Most respondents agreed with the given statements for the beliefs about medication necessity, which indicate that medicines are highly necessary. In contrast, for lower necessity beliefs, the respondents showed uncertainty. On the other hand, the beliefs regarding antihypertensive medications have an overall mean of 2.97 which means that most patient access respondents are uncertain about the said beliefs. As presented in the table, most respondents agreed that natural remedies are safer than medicine. Herbal medicines contain a lot of different compounds which some of which have significant complexities. Plants substances such as polysaccharides, mucilages, and tannins may modulate and modify the effects of "active components" (Karimi et al., 2015). It means that although medicinal plants are widely used and assumed to be safe, they can potentially be toxic due to the different compounds present in them.

The correlation between the demographic profile and clinical data to drug utilization and adherence was computed using Chi-squared and summarized as shown in Table 4. The correlation between the respondents' demographic profile and adherence factors shows that adherence behaviours significantly correlate with the demographic profile in terms of age and family income per month with a pvalue of less than 0.05 .

Medication beliefs and patient-doctor relationships have shown a significant relationship with family income per month of the respondents with a $p$-value of less than 0.05 . However, the remaining variables showed no significant relationship.

Adherence increased with an increase in age up to 69 years and decreased after that point (Kim et al., 2019).

This study shows that the low family income of the respondents affects the patient-doctor relationship. People living in poverty are less likely to have a family physician and obtain preventive and secondary care and more likely to report negative experiences of care (Loignon, 2015).

Citizens with a positive attitude towards medication use would be less risk-conscious and, therefore, more likely to adhere even without using a medication list (StraBner, 
2020). The study's findings show that family income per month has a significant relationship with the patient's beliefs about medicines.

As shown in Figure 1, the correlation of the duration of hypertension and the number of antihypertensive medications were also recognized, with a p-value of 0.7 , which is greater than $0.05(>0.05)$, which means there is no significant relationship between the duration of hypertension and the number of hypertension medications. With these, the duration of a patient's hypertension does not affect the number of antihypertensive drugs he should use in managing hypertension. As for the recommendations provided by the JNC-8 guidelines, the increment of dose and use of multiple medications in managing the disease will vary depending on the severity of most patients with hypertension or the patient's blood pressure category (ACC/AHA and JNC8 hypertension guidelines).check-ups

Further, the correlation of the comorbidities and the number of antihypertensive medications were also identified, as shown in Figure 2. It has a p-value of 0.019 , which is less than $0.05 \quad(<0.05)$, which shows a significant relationship between comorbidities and the number of antihypertensive medications. Combination therapy of antihypertensive medication has a better effectivity than monotherapy, especially if the patient has renal disease or diabetes (Datta, 2016). Most of the respondents used one drug though they presented comorbidities aside from hypertension. The American College of Cardiologists recommends two antihypertensive medications for patients with stage 2 hypertension and an average BP of $20 / 10 \mathrm{mmg} \mathrm{Hg}$ above the target BP. Comorbidities are needed to be considered in this situation since they can exacerbate hypertension or vice-versa. Combination therapy of antihypertensive medication has a better effectivity than monotherapy, especially if the patient has renal disease or diabetes (Datta, 2016). Most of the respondents used one drug though they presented comorbidities aside from hypertension.

Figure 3 shows the correlation of the duration of hypertension and adherence behaviour with the $p$-value of 0.125 , which is greater than 0.05 (>0.05), which means there is no significant relationship between the duration of hypertension and adherence behaviours. Upon analyzing the results for medication adherence, it was found to be higher in patients with a hypertension duration of 11 years and over, with a $p$-value of less than 0.05 (Boratas and Kilic, 2018). Thus, medication adherence increased as the duration of HTN increased (Tumer et al., 2016). This result signifies that the period of hypertension does not affect the compliance of the respondents, which is in contrast with previous studies which state that the patients were more adherent the longer it had been after they were diagnosed with hypertension (Pan et al., 2019). However, this can still be considered reasonable since the duration of a patient's hypertension doesn't affect their adherence.

Figure 4 shows that a p-value of 0.019 is less than 0.05 , indicating a significant relationship between the comorbidities and adherence behaviours. Fifty-five of the hypertensive patients with comorbidities said that their medication adherence affects them 'some of the time.' On the other hand, 91 of them answered 'none of the time. It means that the presence of other or multiple comorbidities affects their adherence behaviour negatively. When there is comorbidity, adherence to antihypertensives falls. In other words, having many medical diseases has been considered as a barrier to optimal drug adherence, leading to nonadherence (Saadat et al., 2015). Hypertension can progress to more serious cardiovascular diseases, and it is a precursor for another type of disease if not managed properly. (Burnier, 2019) the factor contributing to the progression of hypertension is suboptimal medication adherence. With this study, 39 hypertensive patients without comorbidities said that their medication adherence behaviour affects them 'none of the time,' which means that their hypertension is not more likely to progress or become a prelude to another type of disease.

\section{CONCLUSION}

Based on the findings, the researchers concluded that the factors affecting patients' adherence and medication utilization are family income and their age. Patients' family income affects their adherence behaviours, beliefs, and patient-doctor relationship. On the other hand, the age of the patient affects adherence behaviour. Further, most respondents believe that natural remedies are safer compared with their medicines in which it affects their medication utilization. Most of them are also uncertain about their medication concern beliefs, resulting from a lack of education and awareness. Lastly, difficulty in taking the medication at the right time affects their adherence to pharmacotherapy.

\section{RECOMMENDATION}

Based on the conclusion, the researchers would like to recommend the following: 
1. Since the result of the study highlighted that one of the factors affecting patients' adherence is family income, this study can be a basis to reinforce and strengthen the:

a. Universally Healthcare Act is otherwise known as Republic Act No. 11223, Pantawid Pamilyang Pilipino Program (4Ps) known as Republic Act no. 11310 ,

b. Republic Act No. 9502 or the Universally

Cheaper and Quality Medicines Act of 2008 ensures adequate patient access to their medications.

2. Among the dosage regimen difficulties, 'right time' ranked as the highest. In line with this, pharmacists and physicians should enhance their patient counselling services among hypertensive patients and introduce
IoT devices that remind them when they should take their medications.

3. Non-government organizations (NGOs) and the Local Government Unit (LGU) should consider including Losartan as one of the selected prescription drugs available in nonprofit community medicine outlets such as Botikang Barangay.

4. Conduct an interventional study that would improve patients' adherence and medication utilization.

\section{ACKNOWLEDGEMENTS}

The authors wish to thank their families, friends, and research advisers, Mrs. Penuel David, their research consultant Mrs. Regina Jazul, and their research statistician, Mrs. Erlina Mendoza, for their continued support and encouragement to make the study become possible. 


\begin{tabular}{|c|c|c|}
\hline SOCIODEMOGRAPHIC PROFILE & CATEGORIES & PERCENTAGE (\%) \\
\hline \multirow{2}{*}{ Age } & $41-60$ years old & 48.21 \\
\hline & 61 and $A B O V E$ & 30.68 \\
\hline \multirow[t]{2}{*}{ Gender } & Female & 68.13 \\
\hline & Male & 31.87 \\
\hline \multirow{2}{*}{ Educational Attainment } & College Graduate & 38.25 \\
\hline & College Undergraduate & 14.74 \\
\hline \multirow{2}{*}{ Employment Status } & Dependent & 25.90 \\
\hline & Self-Employed & 27.89 \\
\hline \multirow{2}{*}{ Family Income per Month } & BELOW P1,000 & 39.04 \\
\hline & $P 10,000-19,000$ & 18.73 \\
\hline CLINICAL DATA & CATEGORIES & FREQUENCY \\
\hline \multirow{3}{*}{ Comorbidities } & None & 71 \\
\hline & $\begin{array}{c}\text { Endocrine Diseases (Diabetes, Thyroid } \\
\text { diseases, etc.) }\end{array}$ & 50 \\
\hline & $\begin{array}{c}\text { Musculoskeletal System (Arthritis, } \\
\text { Osteoporosis) }\end{array}$ & 39 \\
\hline CLINICAL DATA & CATEGORIES & PERCENTAGE (\%) \\
\hline \multirow{2}{*}{ Medical check-up within the past 3 months } & Less than 4 years & 88.05 \\
\hline & More than 4 years & 11.95 \\
\hline \multirow{2}{*}{ Duration of hypertension } & Greater than 5 years & 49 \\
\hline & Less than 5 years & 51 \\
\hline DRUG THERAPY DATA & CATEGORIES & PERCENTAGE (\%) \\
\hline \multirow[t]{2}{*}{ No. of Antihypertensive medication } & 1 & 49.80 \\
\hline & 2 & 49.80 \\
\hline \multirow{2}{*}{ Cost of Antihypertensive medication } & $<1,000$ & 39.04 \\
\hline & $1,000-1,999$ & 18.73 \\
\hline \multirow{3}{*}{ Antihypertensive medication used } & CATEGORIES & FREQUENCY \\
\hline & Losartan & 146 \\
\hline & Amlodipine & 66 \\
\hline \multirow{2}{*}{$\begin{array}{l}\text { Pharmacological Class of Antihypertensive } \\
\text { Medication }\end{array}$} & Angiotensin Receptor Blockers & 179 \\
\hline & Calcium Channel Blockers & 151 \\
\hline \multirow[t]{2}{*}{ ADR experienced by the patient } & None & 154 \\
\hline & Dizziness & 70 \\
\hline \multirow{2}{*}{$\begin{array}{l}\text { Areas having difficulties with Dosage Regimen } \\
\text { Adherence }\end{array}$} & Right Time & 179 \\
\hline & Right Dose & 71 \\
\hline
\end{tabular}


Table 2: Barriers Affecting Adherence to

Antihypertensive Medication

\begin{tabular}{|c|c|c|}
\hline $\begin{array}{c}\text { Barriers Affecting Adherence to Antihypertensive } \\
\text { Medication }\end{array}$ & 3.04 & Agree \\
\hline
\end{tabular}

Table 3: Factors Affecting the Adherence to Antihypertensive Medication

\begin{tabular}{|c|c|c|}
\hline \multicolumn{3}{|c|}{ Factors Affecting the Adherence to Antihypertensive Medication } \\
\hline Beliefs about Medication & f & $\%$ \\
\hline Low Necessity & 115 & $45.81 \%$ \\
\hline High Necessity & 136 & $54 \%$ \\
\hline Low Concern & 87 & $34.66 \%$ \\
\hline High Concern & 163 & $65.2 \%$ \\
\hline \multicolumn{3}{|l|}{ Behavioural Factors } \\
\hline High Adherence & 88 & $35.06 \%$ \\
\hline Low Adherence & 163 & $64.94 \%$ \\
\hline \multicolumn{3}{|l|}{ Patient doctor relationship } \\
\hline Poor Relationship & 4 & $1.59 \%$ \\
\hline Good Relationship & 247 & $98.80 \%$ \\
\hline
\end{tabular}

Table 4: Correlation of Socio-demographic profile and Factors Affecting the Adherence to Antihypertensive Medication

\begin{tabular}{|c|c|c|c|c|c|c|}
\hline \multirow{2}{*}{$\begin{array}{c}\text { FACTORS } \\
\text { AFFECTING } \\
\text { MEDICATION } \\
\text { ADHERENCE }\end{array}$} & \multicolumn{5}{|c|}{ DEMOGRAPHIC PROFILE } & \multirow[b]{2}{*}{ V.I. } \\
\hline & SEX & $\begin{array}{l}\text { EDUCATIONAL } \\
\text { ATTAINMENT }\end{array}$ & $\begin{array}{l}\text { EMPLOYMENT } \\
\text { STATUS }\end{array}$ & AGE & $\begin{array}{c}\text { FAMILY } \\
\text { INCOME } \\
\text { PER MONTH }\end{array}$ & \\
\hline $\begin{array}{l}\text { Adherence } \\
\text { Behaviour }\end{array}$ & $>0.05$ & $>0.05$ & $>0.05$ & $<0.05$ & $<0.05$ & \multirow{3}{*}{$\begin{array}{c}<0.05= \\
\text { SIGNIFICANT } \\
\text { RELATIONSHIP } \\
>0.05= \\
\text { NO SIGNIFICANT } \\
\text { RELATIONSHIP }\end{array}$} \\
\hline Medication Beliefs & $>0.05$ & $>0.05$ & $>0.05$ & $>0.05$ & $<0.05$ & \\
\hline $\begin{array}{l}\text { Patient-doctor } \\
\text { Relationship }\end{array}$ & $>0.05$ & $>0.05$ & $>0.05$ & $>0.05$ & $>0.05$ & \\
\hline
\end{tabular}




\section{Duration of Hypertension and Number of HTN Medication}

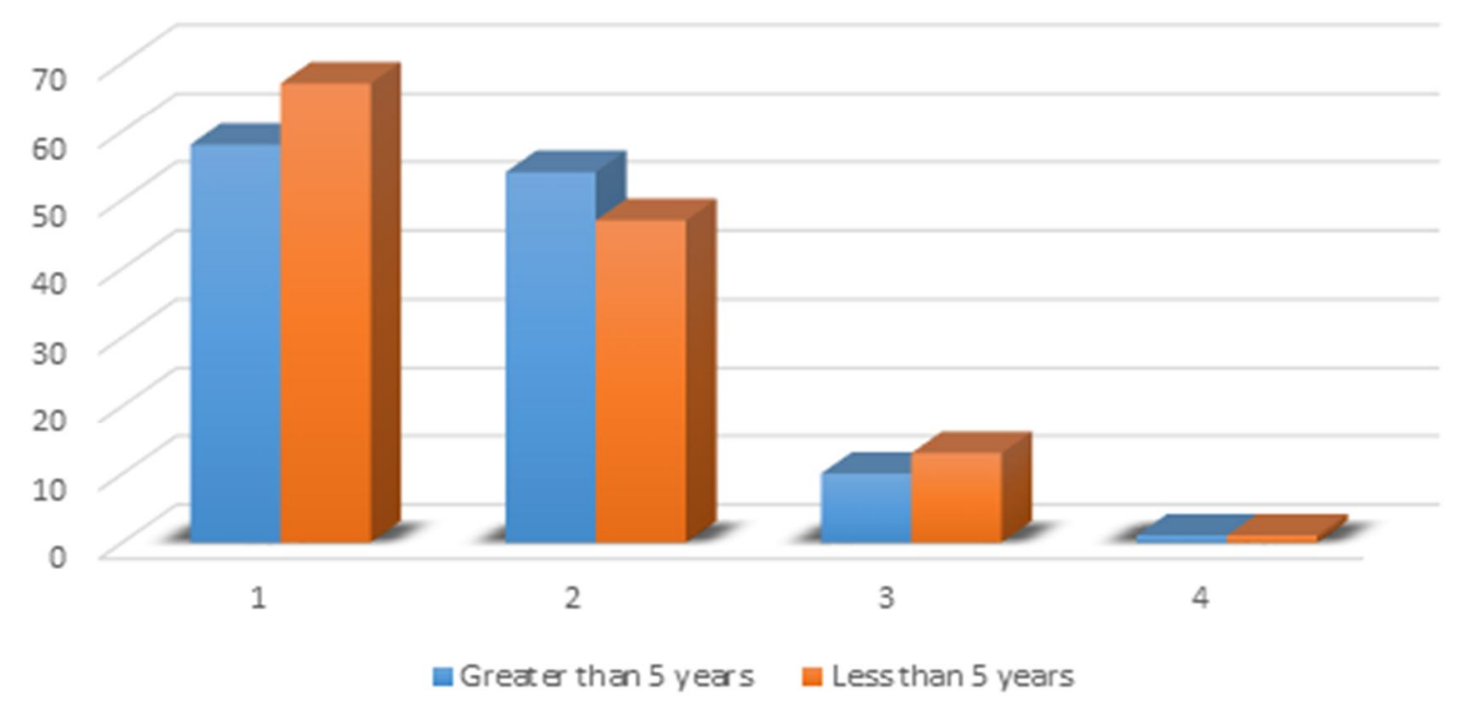

Fig. 1: Correlation Clinical Data and Drug Utilization

\section{Comorbidities and Number of HTN Medication}

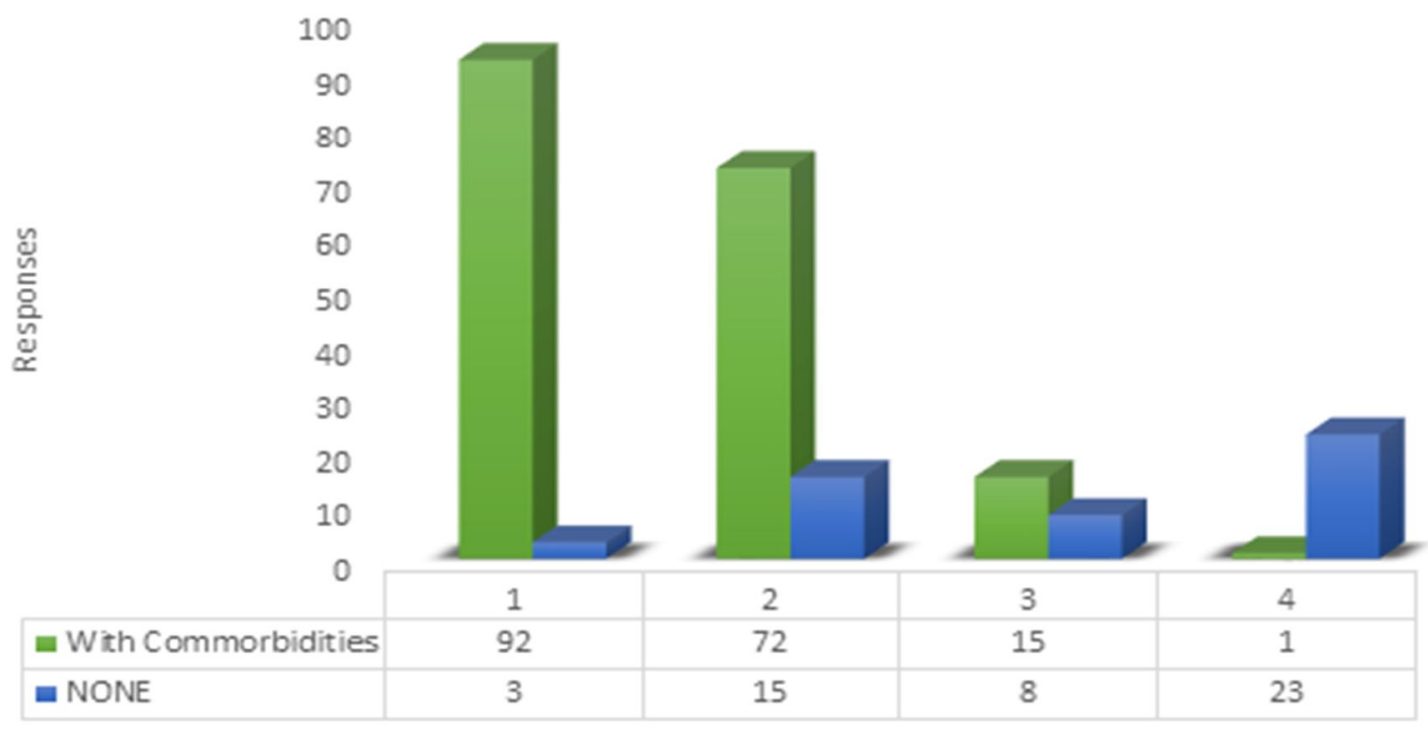

Fig. 2: Comorbidities and Number of Antihypertensive Medication 


\section{Duration of Hypertension and Adherence Behavior}

Never $\quad$ Some of the Time $\quad$ Most of the Time $\quad$ All of the Time

Greate than 5 years

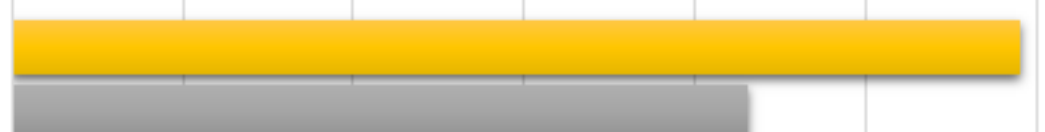

Less than 5 years

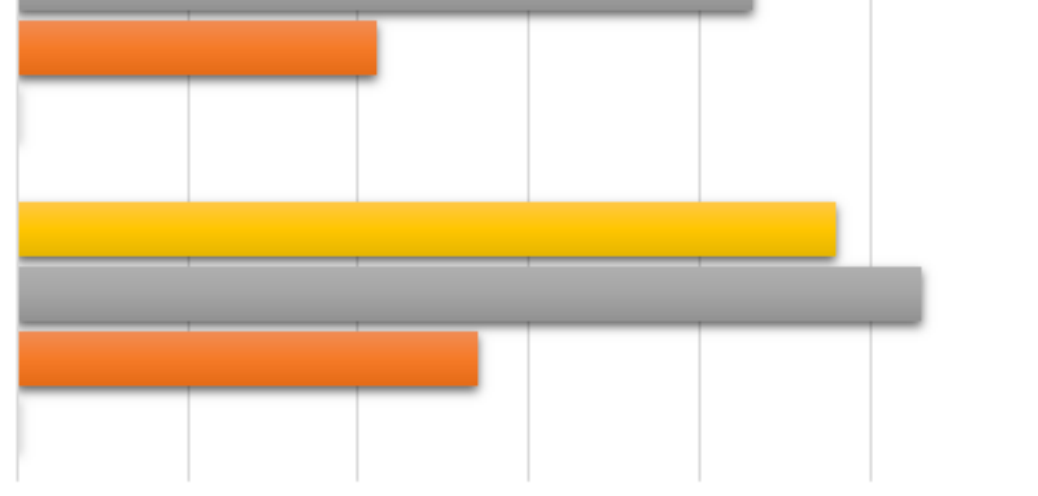

0

10

20

30

40

50

60

Fig. 3: Duration of Hypertension and Adherence Behaviour

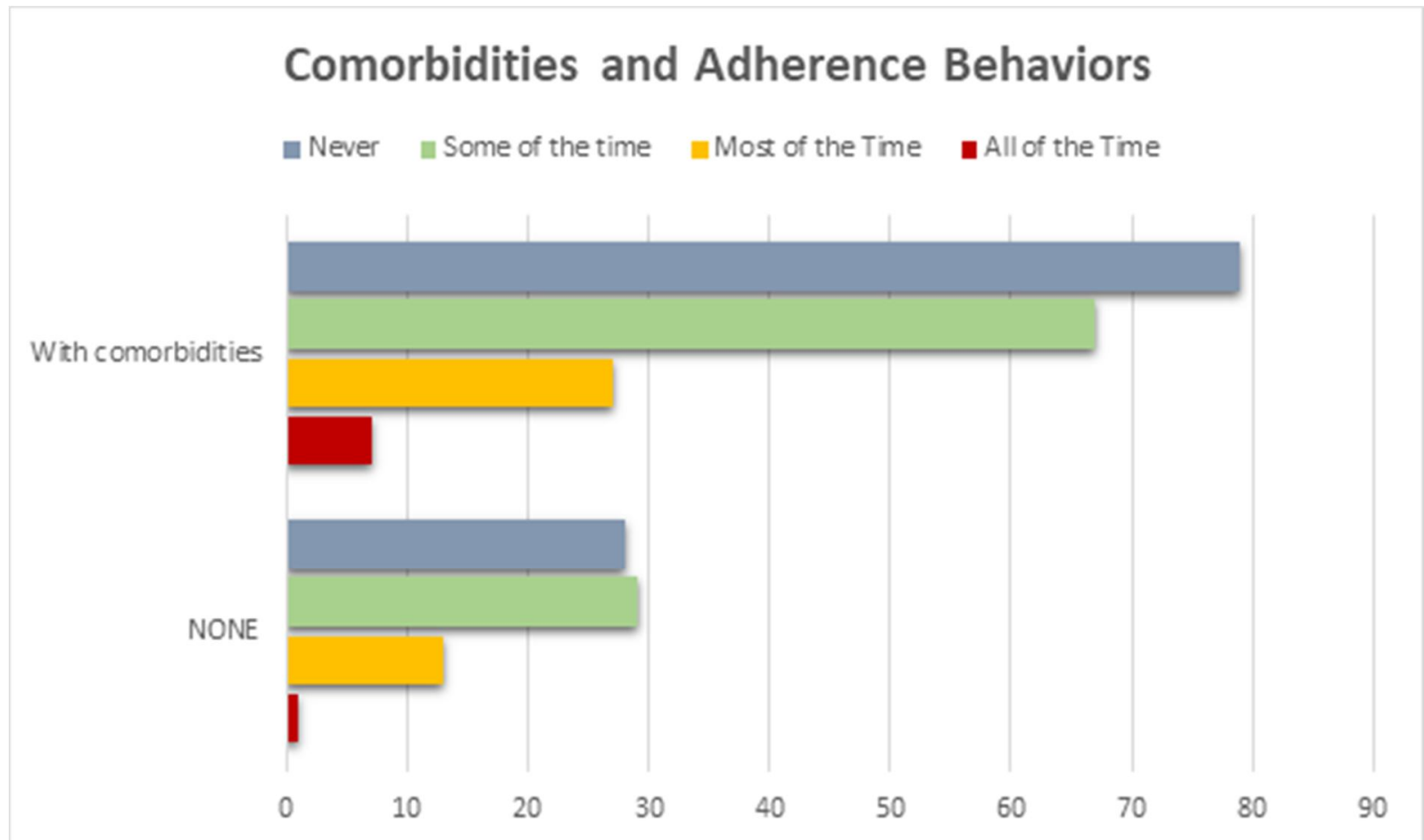

Fig. 4: Comorbidities and Adherence Behaviour 


\section{REFERENCES}

1. ACC/AHA and JNC-8 hypertension guidelines. 2017. https://www.aanpcert.org/newsitem?id $=94$.

2. Adejumo O, Okaka E and lyawe I. Prescription pattern of antihypertensive medications and blood pressure control among hypertensive outpatients at the University of Benin Teaching Hospital in Benin City, Nigeria. Malawi Med J. 2017;29(2):113-117.

3. Ahmad A and Oparil S. Hypertension in Women: Recent Advances and Lingering Questions. Hypertension (Dallas, Tex. : 1979). 2017 Jul;70(1):19-26.

4. Attaei MW, Khatib R and McKee M. Availability and affordability of blood pressure-lowering medicines and the effect on blood pressure control in high-income, middle-income, and lowincome countries: an analysis of the PURE study data. Lancet Public Health. 2017;2(9):e411-e419.

5. Boratas $S$ and Kilic HF. Evaluation of medication adherence in hypertensive patients and influential factors. Pak J Med Sci. 2018;34(4):959-963.

6. Burnier $M$. Drug adherence in hypertension. Pharmacol Res. 2017;125(Pt B):142-149.

7. Datta S. Utilization Study of Antihypertensives in a South Indian Tertiary Care Teaching Hospital and Adherence to Standard Treatment Guidelines. J Basic Clin Pharm. 2016;8(1):33-37.

8. Mann JF. In the Choice of drug therapy in primary hypertension. 2020.https://www.uptodate.com/conte nts/choice-of-drug-therapy-in-primaryessential-hypertension

9. Sison J, Divinagracia R and Nailes J. Asian management of hypertension: Current status, home blood pressure, and specific concerns in Philippines (a country report). J ClinHypertens (Greenwich). 2020;22(3):504-507.

10. Straßner C, Mahler $C$ and Strauß B. Medication beliefs and use of medication lists - is there a connection? Results from a beforeand-after study in Germany. BMC Geriatr. 2020;20(1):116. Published 2020 Mar 30.

11. Tumer A, Bayguga $M$, Dereli $F$ and Uysal D. The compliance level of treatment of hypertensive patients. $\mathrm{J}$ CardiovascNurs. 2016;7(13):105-113.

12. Wenger NK, Arnold A and BaireyMerz CN. Hypertension Across a Woman's Life Cycle. J Am Coll Cardiol. 2018;71(16):1797-1813.

13. Pan J, $W u ~ L$ and Wang $H$. Determinants of hypertension treatment adherence among a Chinese population using the therapeutic adherence scale for hypertensive patients. Medicine (Baltimore). 2019;98(27):e16116.

14. Saadat Z, Nikdoust F and AerabSheibani H. Adherence to Antihypertensives in Patients With Comorbid Condition. Nephrourol Mon. 2015;7(4):e29863.

15. World Health Organization. Hypertension. 2019. https://www.who.int/news-room/q-adetail/noncommunicable-diseaseshypertension

16. Kim SJ, Kwon OD and Han EB. Impact of number of medications and age on adherence to antihypertensive medications: A nationwide populationbased study. Medicine (Baltimore). 2019;98(49):e17825.

17. Karimi A, Majlesi $M$ and RafieianKopaei M. Herbal versus synthetic drugs; beliefs and facts. J Nephropharmacol. 2015;4(1):27-30.

18. Loignon C, Hudon C and Goulet É. Perceived barriers to healthcare for persons living in poverty in Quebec, Canada: the EQUIhealThY project. Int J Equity Health. 2015;14:4. 